\title{
Pandemia do Coronavírus no Brasil: Impactos no Território Cearense
}

Conoravirus Pandemic in Brazil: Impacts in the Territory of Ceará

Pandémie de Coronavirus au Brésil : Répercussions chez le Territoire de Ceará

Pandemia de coronavirus en Brasil: impactos en el territorio Cearense

José Borzacchiello da Silva e Alexsandra Maria Vieira Muniz

\section{(2) OpenEdition}

Journals

\section{Edição electrónica}

URL: http://journals.openedition.org/espacoeconomia/10501

DOI: 10.4000/espacoeconomia.10501

ISSN: 2317-7837

\section{Editora}

Núcleo de Pesquisa Espaço \& Economia

\section{Refêrencia eletrónica}

José Borzacchiello da Silva e Alexsandra Maria Vieira Muniz, « Pandemia do Coronavírus no Brasil: Impactos no Território Cearense ", Espaço e Economia [Online], 17 | 2020, posto online no dia 07 abril 2020, consultado o 21 abril 2020. URL : http://journals.openedition.org/espacoeconomia/10501 ; DOI : https://doi.org/10.4000/espacoeconomia.10501

Este documento foi criado de forma automática no dia 21 abril 2020.

(c) NUPEE 


\title{
Pandemia do Coronavírus no Brasil: Impactos no Território Cearense
}

\author{
Conoravirus Pandemic in Brazil: Impacts in the Territory of Ceará \\ Pandémie de Coronavirus au Brésil : Répercussions chez le Territoire de Ceará \\ Pandemia de coronavirus en Brasil: impactos en el territorio Cearense
}

José Borzacchiello da Silva e Alexsandra Maria Vieira Muniz

1 Hoje mais uma nova praga assusta as cidades e coloca os cidadãos de prontidão. Tratase do Covid-19, o novo Coronavírus, doença infecciosa que ocupa horas e horas do noticiário da imprensa e dos meios digitais nas redes sociais com suas consequências nos diferentes territórios e segmentos sociais.

2 Medidas excepcionais são tomadas considerando a rapidez de seu contágio, a duração do tratamento e as altas taxas de letalidade, o que resultou na declaração da Organização Mundial da Saúde - OMS de que vivemos uma pandemia considerando a rapidez como se espalhou pelo mundo. O Coronavírus é transmitido por ar e por mucosas. De Wuhan na China, onde surgiu no final de 2019, propagou-se pelo mundo e o tráfego aéreo é apresentado como o principal difusor da doença com alto grau de transmissão. O morcego aparece até agora como o principal vetor do surto iniciado em Wuhan, gigantesca metrópole com mais de 10 milhões de habitantes localizada na China central. A pandemia provocada pelo Coronavírus colocou as cidades em alerta, especialmente as grandes que apresentam altas densidades e facilitam a propagação da doença. O clima de pânico está instaurado e emerge a certeza que o mundo não será o mesmo quando superada essa fase de expansão da contaminação do Coronavírus.

3 Um complexo xadrez geopolítico insere a pandemia desse vírus no contexto de bruscas mudanças no cotidiano globalizado. Nas diferentes crises mundiais datadas do pós Segunda Guerra, a pandemia atual parece superar a Guerra Fria, o ataque das torres gêmeas do World Trade Center de 11 de Setembro e o crach da bolsa de 2008 que reacendeu o drama vivido pela crise da depressão dos anos 30 do século passado. A oscilação nas principais bolsas de valores tem gerado ansiedade e temores entre os investidores. A situação se agravou, por conseguinte foram tomadas medidas pelas 
autoridades sanitárias de vários países que optaram pela prática do isolamento social que consiste na recomendação para que as pessoas fiquem em suas casas em quarentena que dura em média duas semanas. Essas medidas visam reduzir a propagação da doença e impedir o colapso imediato das redes hospitalares, incapazes de responder ao aumento acentuado do número de infectados.

4 Várias hipóteses têm sido formuladas diante da preocupação em compreender a origem e propagação da doença provocada pelo Covid-19. Em interessante artigo publicado no El Pais ${ }^{1}$, Debora Diniz e Giselle Carino dizem que

A epidemia do vírus corona parece uma atualização das aulas de Michel Foucault sobre biopolítica, segurança e territórios. A biopolítica é o poder que organiza as políticas da vida, isto é, são táticas que regulam que corpos devem viver e quais podem ser descartáveis. A explosão de uma epidemia é um momento efusivo à biopolítica: em nome da proteção coletiva se controlam os corpos, se traçam fronteiras reais ou imaginárias à saúde.

5 As autoras são precisas quando falam do controle dos corpos, inclusive as escolhas dos que devem viver mediante as pressões vigentes nos serviços hospitalares que se mostram incapazes de atender a pressão da demanda.

6 Como consequência da propagação da pandemia se avolumam as notícias de hospitais lotados e sem números suficientes de EPI(Equipamentos de Proteção Individual) e demais suporte(leitos, recursos humanos, respiradores, medicamentos e testes laboratoriais) que venha corresponder a demanda, eventos adiados, vôos cancelados e pessoas de diferentes nacionalidades em busca de voltar para seus países de origem, mas a geopolítica e as fronteiras que se fortalecem neste presente limitam a mobilidade no espaço produtivo, estando a velocidade das informações e o acesso heterogêneo de diferentes atores aos meios tecnológicos a reduzir o vazio e a distância dos entes queridos. De um total de 15.000 brasileiros nesta situação de fechamentos de fronteiras foram tomadas medidas que atenderam a 8.300, existindo ainda um quantitativo de mais de 7.000 aguardando solução com possíveis vôos chats e fretamento de aeronaves por parte da gestão pública federal brasileira e as autoridades que os representam em diferentes territórios².

70 que até então para muitos era motivo de regozijo e status social adentrar em territórios transfronteiriços, tem se transformado em pesadelo para os que não conseguem retornar para casa, em virtude das medidas tomadas na escala mundial para conter a pandemia que nos faz lembrar a gripe espanhola e a peste negra.

Em tempos de restrição da mobilidade recorre-se a diferentes plataformas digitais para reuniões com limite ao tempo e quantidade de pessoas conectadas - Google Hangouts Meet, Zoom, são alguns exemplos.

9 Sentindo-se como pássaros presos em construções humanas, sem poder alçar nem mesmo pequenos vôos (muitos são os que agradecem ao criador por ter um teto, contrariando aqueles que são contra a teoria do criacionismo, tendo suas teorias como verdades absolutas, se portando como deuses do conhecimento científico, não atentando para o relativismo da própria ciência, muitas vezes exercendo o autoritarismo ou porque não dizer o assédio moral, em que uma teoria é então relevante ou "correta" não porque é verdadeira, mas sim porque é defendida pelo mais forte, envolvendo relações de poder e troca de "favores" e assim se deixam levar por vãs discussões que permeiam a mídia). Mas, fato é que por mais que ressurjam teorias diante das reações singulares de cada um frente a pandemia do Covid-19, o que se 
coloca também no emaranhado de notícias que nos chegam através das redes sociais são previsões futuristas, levando muitos a acreditar que estaríamos vivenciando as profecias apocalípticas, mas como diria Marshall Berman (1993) tudo que é sólido desmancha no ar.

Pepe Escobar no texto A China engalfinhada em uma guerra hibrida com os Estados Unidos ${ }^{3}$ parte da hipótese que "o coronavírus é uma bio-arma muito poderosa, embora incapaz de provocar o Apocalipse, o coloca como o veículo perfeito para um controle social generalizado - em escala global".

11 Soma-se às diferentes facetas do atual quadro, as precárias condições de moradia nas favelas e periferias do país que é motivo de intensa preocupação. Ademais, a grande quantidade de famílias que dependem do trabalho informal nesses territórios e que estão com sua renda comprometida só revela que o Coronavírus é mais que uma pandemia, é também uma crise social e econômica, e mais ainda uma questão geopolítica, de luta de classes e o aprofundamento do capitalismo em sua versão mais perversa.

12 As cidades brasileiras estão doentes. Em quase todas elas, a natureza urbana degradada agoniza. São sérios os problemas de moradia caracterizados pelas péssimas condições das habitações agravados pelos problemas ligados ao saneamento básico, compreendendo o abastecimento de água, o esgotamento sanitário, a pavimentação de vias, o sistema de galerias pluviais e o serviço de coleta do lixo. Em momentos de epidemias que têm sido frequentes, os mais vulneráveis são as vítimas preferenciais.

No Brasil, com mais de 11.298 mil casos confirmados do novo Coronavírus e 489 mortes conforme as secretarias estaduais de Saúde divulgaram neste domingo (5 de abril de 2020), o epicentro da pandemia do Coronavírus é a cidade de São Paulo, tendo sido confirmado o primeiro caso em 26 de fevereiro e o primeiro óbito em 17 de março, desde o primeiro caso confirmado no país, passados 25 dias, ou seja em 21 de março, o número saltou de 1 para 1.000, passados 6 dias, ou seja em 27 de março registravam-se 2.000 novos casos, com mais 3 dias - em 31 de março - já registrava-se mais 3.000 casos confirmados, chegando ao 5 de abril com 4.620mil infectados. Em poucos dias a doença se propagou e já cobre todos os estados da federação, como pode ser visto na figura1 a seguir: 


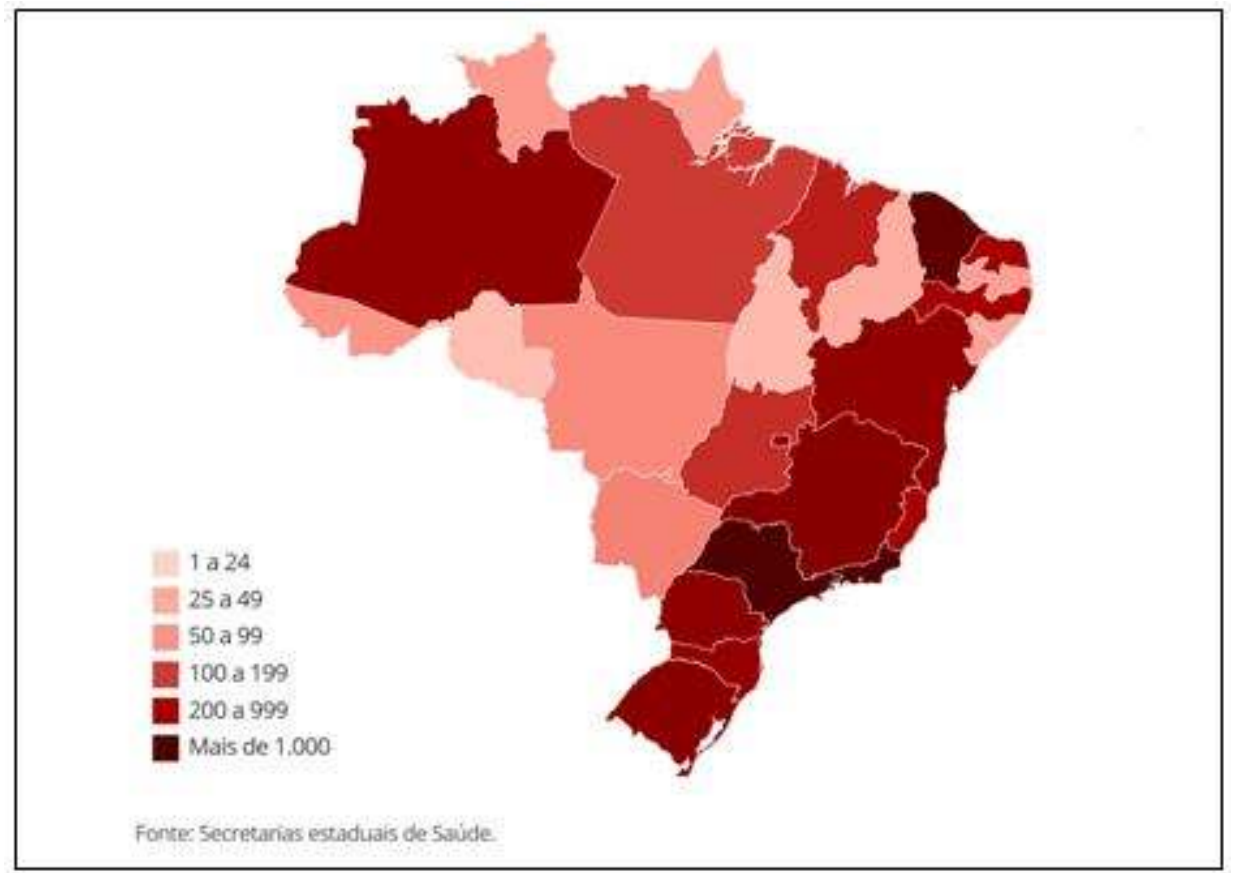

Fonte indireta: https://g1.globo.com/bemestar/coronavirus/noticia/2020/04/06/casos-decoronavirus-no-brasil-em-6-de-abril.ghtml

O número de infectados por Estados alteram-se frequentemente. O Ceará tem se mantido na terceira posição, tendo à frente São Paulo e Rio de Janeiro que são estados mais populosos que o Ceará (9,1 milhões de habitantes). No dia 26 de março de 2020 era 238 o número de infectados no Estado do Ceará, com o registro de 3 mortes. Já em 27 de março passou para 282 o número de casos de Covid-19, permanecendo o número de óbitos. A figura 2 permite verificar que o Coronavírus vem se expandindo para além da capital e sua região metropolitana. 
Figura 2: Casos de Covid-19 no Estado do Ceará (26 a 27 de março de 2020)

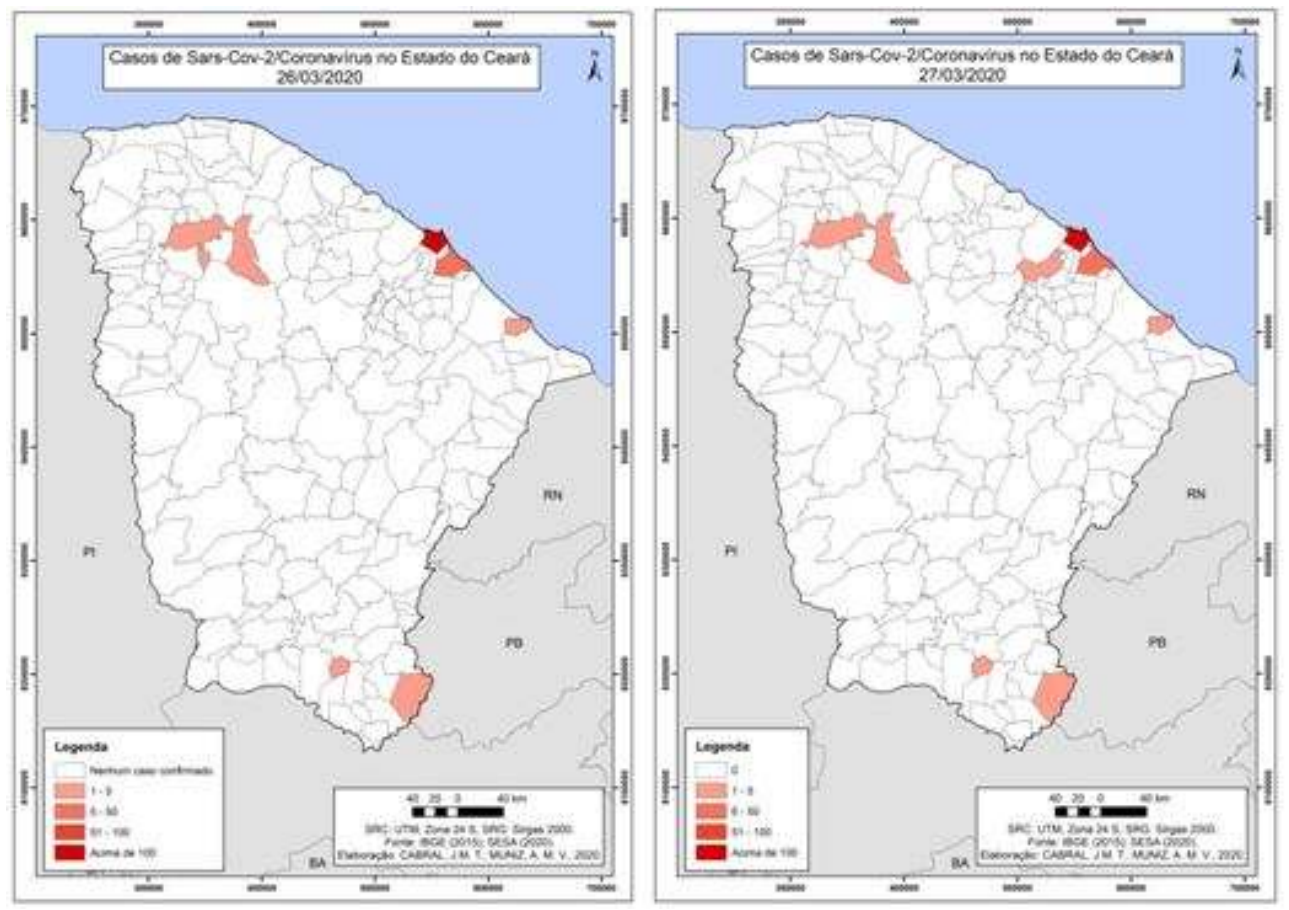

15 Como pode ser visto na figura 3 enquanto no dia 28 de março de 2020, foram confirmados 322 casos de Covid-19 no Estado com 4 mortes, em 29 de março já eram 338 com 5 óbitos. A velocidade de difusão já incluía no dia 28 Caucaia na RMF com interiorização também para Quixadá, além dos municípios verificados na figura 3: Aquiraz, Fortim, Juazeiro do Norte, Sobral, Maranguape, Mauriti. 
Figura 3 - Casos de Covid-19 no Estado do Ceará (28 de março de 2020)

\section{MAPA DA DISTRUIÇÃO DOS CASOS DE COVID-19 NO CEARÁ, EM 28 DE MARÇO DE 2020}

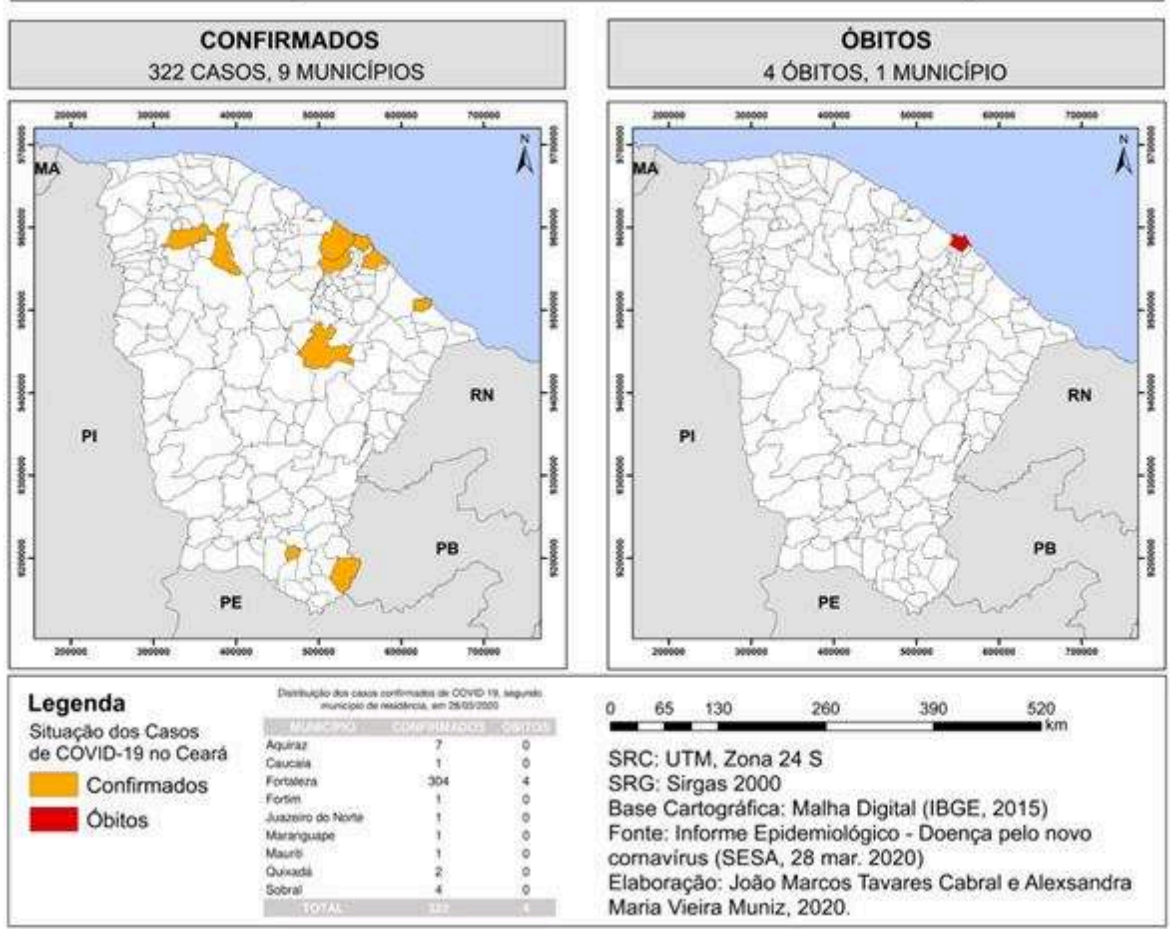

16 Assim, podemos afirmar pela análise das figuras supracitadas que a maior parte dos casos do Estado do Ceará se concentram na capital e os demais na região metropolitana e interior do Estado com tendência para difusão menos concentrada nos demais municípios do Estado, embora as medidas que estão sendo tomadas pela gestão estadual venham contribuindo para que não aumente ainda mais a velocidade de ocorrências.

Entretanto, a territorialização do Covid-19, com variação ao longo do tempo só reflete a velocidade de propagação, sendo a transmissão já comunitária que é quando o estágio da doença está ocorrendo dentro do próprio Estado. É tão dinâmico o processo em curso, que o número de casos se alteram em uma velocidade frenética. A evolução dos casos no território cearense pode ser vista na Figura 4. 
Figura 4 - Coronavírus: avanço de casos confirmados por UF

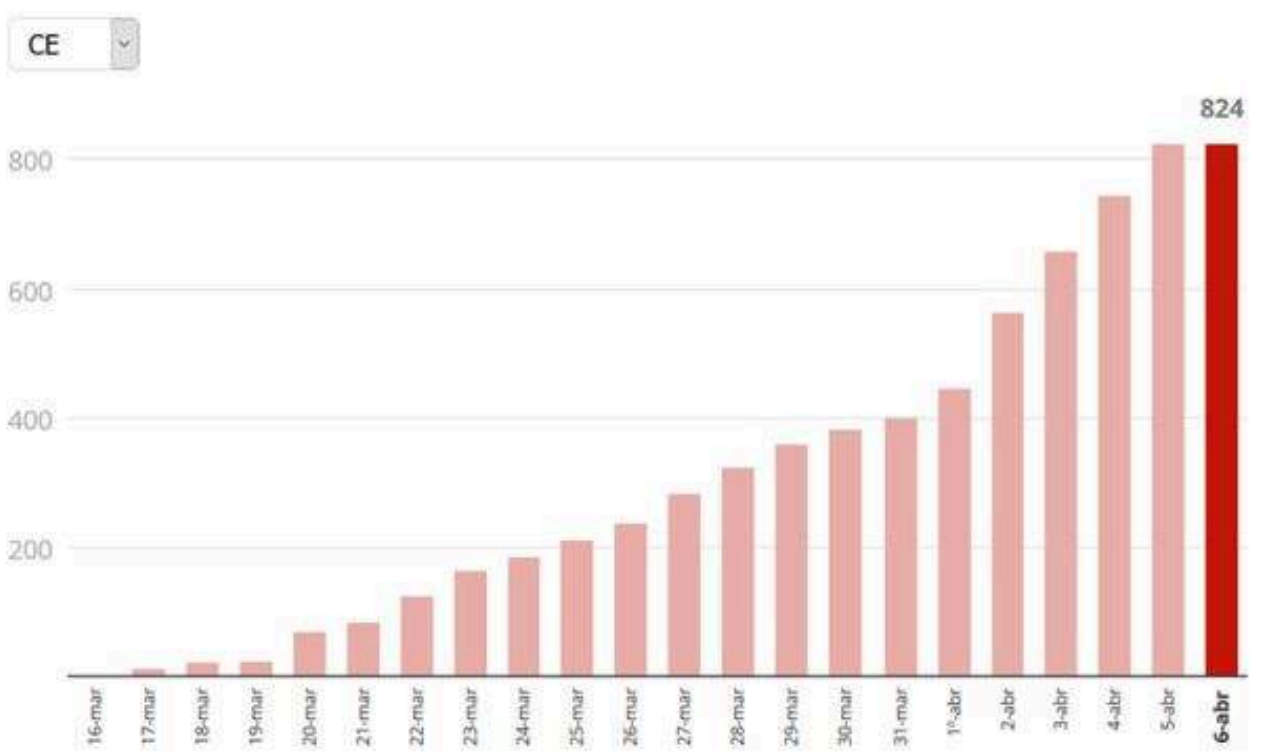

Fonte: Secretarias estaduais de Saúde

Fonte indireta: https://g1.globo.com/bemestar/coronavirus/noticia/2020/04/02/casos-decoronavirus-no-brasil-em-2-de-abril.ghtml

Como pode ser analisado pela figura 4, os números de casos com Covid no Ceará cresce em progressão geométrica, pois em 7 dias o número de casos saltou de 11 para 164, com duas semanas mais que duplica já eram 382 e com 3 semanas só evidencia a velocidade de crescimento para mais que o dobro quando chega no dia 06 de abril a 824 casos confirmados e 26 óbitos. Muitos devem se questionar o porquê do destaque do Estado do Ceará, sendo o terceiro com maior quantidade de casos no território nacional. Isto deve-se a intensificação dos casos acompanhados da rapidez da testagem com aquisição de kits para diagnóstico do Coronavírus em prazo de até quatro horas, o que tem favorecido a notificação diária pela Sesa (Secretaria da Saúde do Estado do Ceará). Assim, é possível acompanhar o comportamento da epidemia com o aumento da vigilância epidemiológica e a continuidade dos planos estratégicos colocados em ação. Em outras palavras, o aumento da investigação dos casos de Covid-19 no território cearense com deteç̧ão de novos casos em curto espaço de tempo é que tem dado maior visibilidade do Ceará na mídia, evidenciando um número bem maior de casos que em outros estados do Nordeste, mas fato é que devido a insuficiência na quantidade de testes e com o aumento do número de pacientes com demora pelo resultado registrado em notícias de jornal no início de abril, as taxas de contaminação e mortalidade podem ser maiores do que os apresentados em números oficiais no país.

Se na escala nacional Fortaleza está na terceira posição em número de casos, na escala estadual é Fortaleza que ocupa a primeira posição, concentrando o maior número de casos.

Como supramencionado, a pandemia do Covid-19 é o principal assunto global do momento afetando a todos direta ou indiretamente, em particular, em Fortaleza, aqueles que vivem em condições precárias na extensa faixa periférica que avança pelo espaço metropolitano e com extrema velocidade se territorializa em diferentes direções no espaço Cearense, se interiorizando. 
21 Já no Século XIX Fortaleza foi palco de uma calamidade pública de triste lembrança. Uma epidemia de varíola dizimou parte da população da cidade e há registros de 1004 mortos num só dia. Não havia meios de garantir enterros dignos para tantos defuntos. As condições sanitárias da cidade não eram favoráveis e muitos cadáveres foram atirados em vala comum. A proliferação de doenças num contexto de extrema miséria e abandono expunha os flagelados da seca de 1878 oriundos do sertão sofrido pelos efeitos de prolongada estiagem, o que resultou num caos que dominou a cidade e deixou muitas sequelas, sendo a formação de enormes acampamentos de famintos e esfarrapados prestes a morrer. Essa chaga atravessa a história de Fortaleza, daí a razão de um esquecimento, de um fato histórico pouco lembrado na memória urbana no processo de formação da cidade. Várias favelas foram erguidas nos locais desses acampamentos dos tempos da epidemia de varíola. Os pobres flagelados vitimados pela grande seca morreram como sujeitos opacos e anônimos, idêntico ao modo de vida que tinham sertão à dentro. As condições miseráveis dos sertanejos não incomodavam a elite fortalezense que se portava indiferente ao sertão, nesse mundo distante marcado pela invisibilidade. A elite da cidade era muito mais voltada para o exterior, explorando os meios que uma cidade litorânea oferecia. Se as condições sanitárias de antanho eram precárias no final do XIX, ainda o são nos dias de hoje nessa cidade turística e dinâmica mais conhecida pela beleza e encantos de suas praias.

Ademais, chega-se ao período sazonal de maior incidência de constantes epidemias de dengue, zika, chikungunya, sarampo e influenza. Essas doenças de forte influência ambiental contaminam mais os que se encontram em situação de vulnerabilidade social. Elas dizimam vidas, enfraquecem as pessoas, especialmente os pobres. Já o Covid-19 contagia ricos e pobres, razão pela qual as atenções dos governos são outras diante do perfil dos casos já confirmados.

o Ceará tem uma explosão de casos do Covid-19 do fim do mês de março para início do mês de abril. Se no dia 31 de março eram 401 casos no Ceará com 7 óbitos, já no dia 02 de abril o número de casos chega a 445 e 9 óbitos.

Pela Tabela 1 podemos ver que Fortaleza continua concentrando os casos confirmados com 413 casos, logo após aparece Aquiraz com 14, Sobral com 5, Quixadá 2 e o restante dos municípios da tabela com um caso. Enquanto Fortaleza registra 6 óbitos, Santa Quitéria que pertence a região de saúde norte confirmou a primeira morte no dia 31 de março e no dia primeiro de abril foi Eusébio e Tianguá. 
Tabela 1- Distribuição dos casos confirmados de COVID-19 por município de residência-Ceará, 01 de abril de $2020^{4}$

\begin{tabular}{|l|c|c|c|c|}
\hline \multicolumn{1}{|c|}{ MUNICIPIO } & CONFIRMADOS & $\begin{array}{c}\text { INCIDENCIA POR } \\
100 \text { MIL HAB }\end{array}$ & OBITOS & LETALIDADE (\%) \\
\hline Aquiraz & 14 & 17,6 & - & - \\
\hline Beberibe & 1 & 1,9 & - & - \\
\hline Caucaia & 1 & 0,3 & - & - \\
\hline Eusébio & 1 & 1,9 & 1 & 100,0 \\
\hline Fortaleza & 413 & 15,6 & 6 & 1,5 \\
\hline Fortim & 1 & 6,1 & - & - \\
\hline Itaitinga & 1 & 2,5 & - & - \\
\hline Juazeiro do Norte & 1 & 0,4 & - & - \\
\hline Maracanaú & 1 & 0,4 & - & - \\
\hline Maranguape & 1 & 0,8 & - & - \\
\hline Mauriti & 1 & 2,1 & - & - \\
\hline Quixadá & 2 & 2,3 & - & - \\
\hline Santa Quitéria & 1 & 2,3 & 1 & - \\
\hline Sobral & 5 & 2,4 & - & 100,0 \\
\hline Tianguá & 1 & 1,3 & 1 & 2,0 \\
\hline TOTAL & 445 & 4,4 & 9 & \\
\hline
\end{tabular}

Fonte: SESA (Secretaria de Saúde do Ceará)

Segundo o informe epidemiológico da doença pelo novo Coronavírus (COVID-19) de 01 de abril ${ }^{5}$ :

Dentre os casos confirmados, 237(59,1\%) estão na faixa etária de 20 a 49 anos de idade e a maior incidência é na faixa etária de 50 a 69 (11,8 casos por 100 mil habitantes para os homens e 7,9 casos por 100 mil habitantes entre as mulheres). Os homens foram mais acometidos, representando 53,1\%(213/401) das infecções pelo COVID-19.

No dia 5 de abril, o número de casos no Ceará chega a 824 com 26 óbitos e quase 4 mil casos suspeitos (ver Figura 5). Com este quadro, o Ceara é apontado pelo Ministério da Saúde como um dos Estados, com aumento agudo dos casos de Coronavírus, com taxa de letalidade da doença de $2,79 \%$. 
Figura 5 - Casos de Covid-19 no Estado do Ceará (5 de abril de 2020)

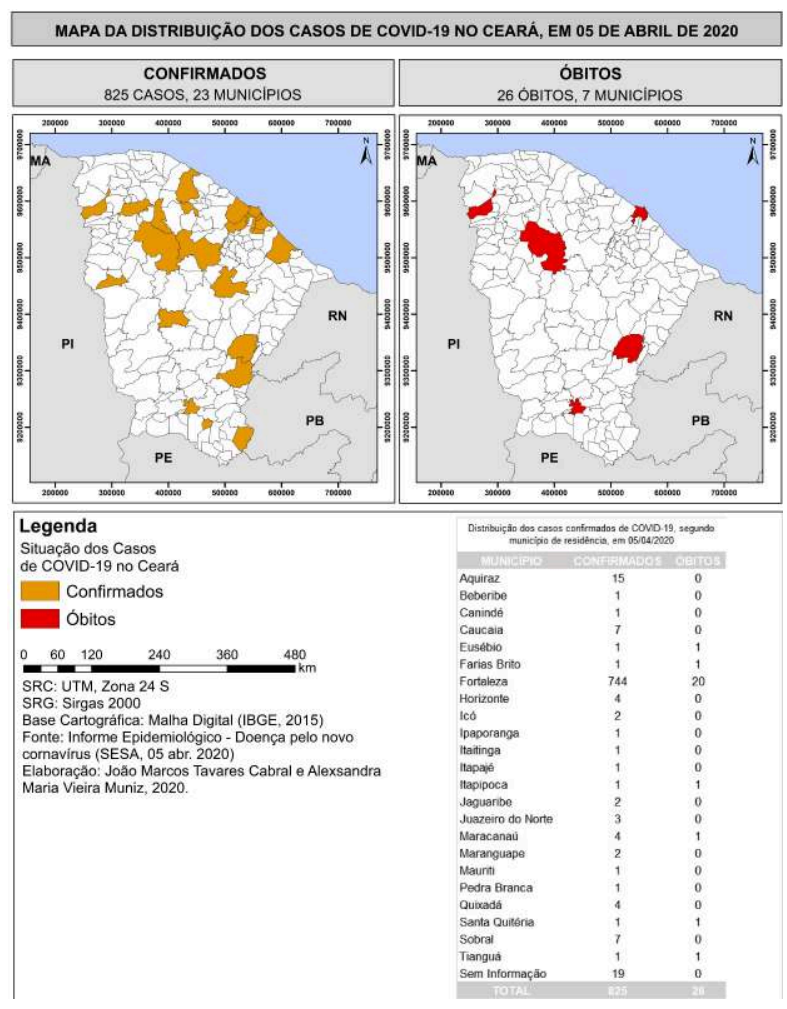

27 Como pode ser verificado na figura 5 e pela análise comparativa da territorialização do Covid-19, a pandemia já se expandiu no território cearense, incluindo até o momento 23 municípios, embora o maior número de casos seja na capital.

No que tange aos problemas ambientais, no caso de Fortaleza a pandemia do Covid-19 assume condições catastróficas. Rios, lagoas e córregos poluídos, destruição das dunas, desmatamento generalizado com acentuada redução de áreas verdes, especialmente nos bairros periféricos mais densamente ocupados, além de muitas construções irregulares. Canos e tubulações atiram esgotos, águas servidas e outros dejetos em suas águas agora praticamente paradas. A figura 6 a seguir elucida essas afirmações a partir do IDH dos bairros da cidade.

Figura 6: IDH por bairros de Fortaleza

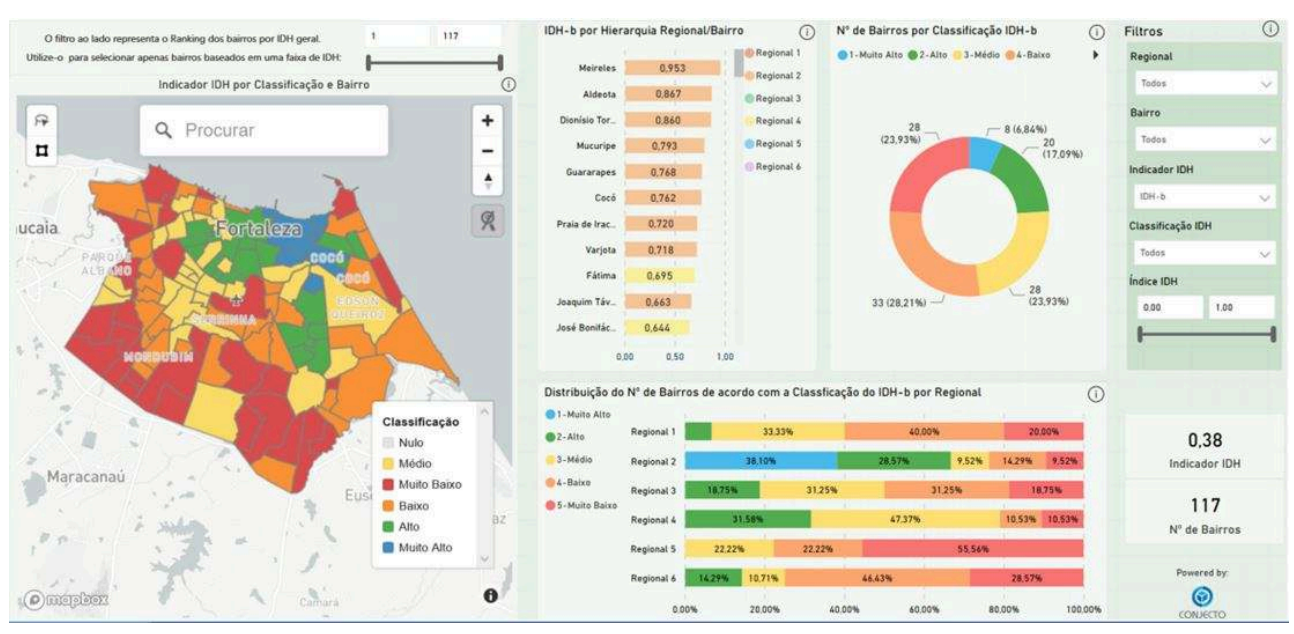

Fonte: Anuário do Ceará, 2019/2020 
Como se sabe o Índice de Desenvolvimento Humano Municipal (IDH-M) contempla três indicadores: média de anos de estudo do chefe de família, taxa de alfabetização e renda média do chefe de família (em salários mínimos). Quanto mais próximo da nota 1,0 mais desenvolvido é o bairro. De acordo com o ultimo Anuário do Ceará (2019-2020), vinte e nove bairros possuem IDH-M médio (entre 0,500 e 0,953). São eles: Farias Brito, Parque Iracema, Bom Futuro, Damas, Cambeba, Luciano Cavalcante, Papicu, Centro, Cidade 2000, Cidade dos Funcionários, Parreão, Parque Manibura, Parque Araxá, Amadeu Furtado, São Gerardo, Parquelância, Benfica, De Lourdes, José Bonifácio, Joaquim Távora, Fátima, Varjota, Praia de Iracema, Cocó, Guararapes, Mucuripe, Dionísio Torres, Aldeota, Meireles. Por sua vez, os demais 92 bairros de Fortaleza de um total de 121 têm índice considerado baixo (entre 0 e 0,499). Como pode ser verificado na figura 6 são poucos os bairros que apresentam índices elevados.

o que fazer para minorar ou corrigir essas e outras irregularidades que comprometem o bem-estar e a qualidade de vida independente da atual pandemia? Na América Latina, especialmente no Brasil, as cidades cresceram muito, em proporções descomunais. No início, os especialistas denominaram de "inchaço", esse crescimento desmesurado das cidades. Não era só a forma urbana que se modificava. Fortaleza é feita de gente. Gente que trabalha, come, bebe, estuda, se movimenta, se diverte, gera conflitos, contrai doenças. Toda a dinâmica da vida está presente nas cidades de seu espaço metropolitano. Com uma enorme gama de problemas, Fortaleza espelha também a realidade da região e do país onde ela está inserida.

Diante disto, Fortaleza (vide Figura 7) e sua região metropolitana constituem territórios ideais para propagação do Coronavírus. Ele é transmitido de forma silenciosa sem que a pessoa contaminada perceba que esteja com problema de saúde.

Figura 7 - Ocorrência dos registros dos casos infectados pelo Coronavírus em Fortaleza

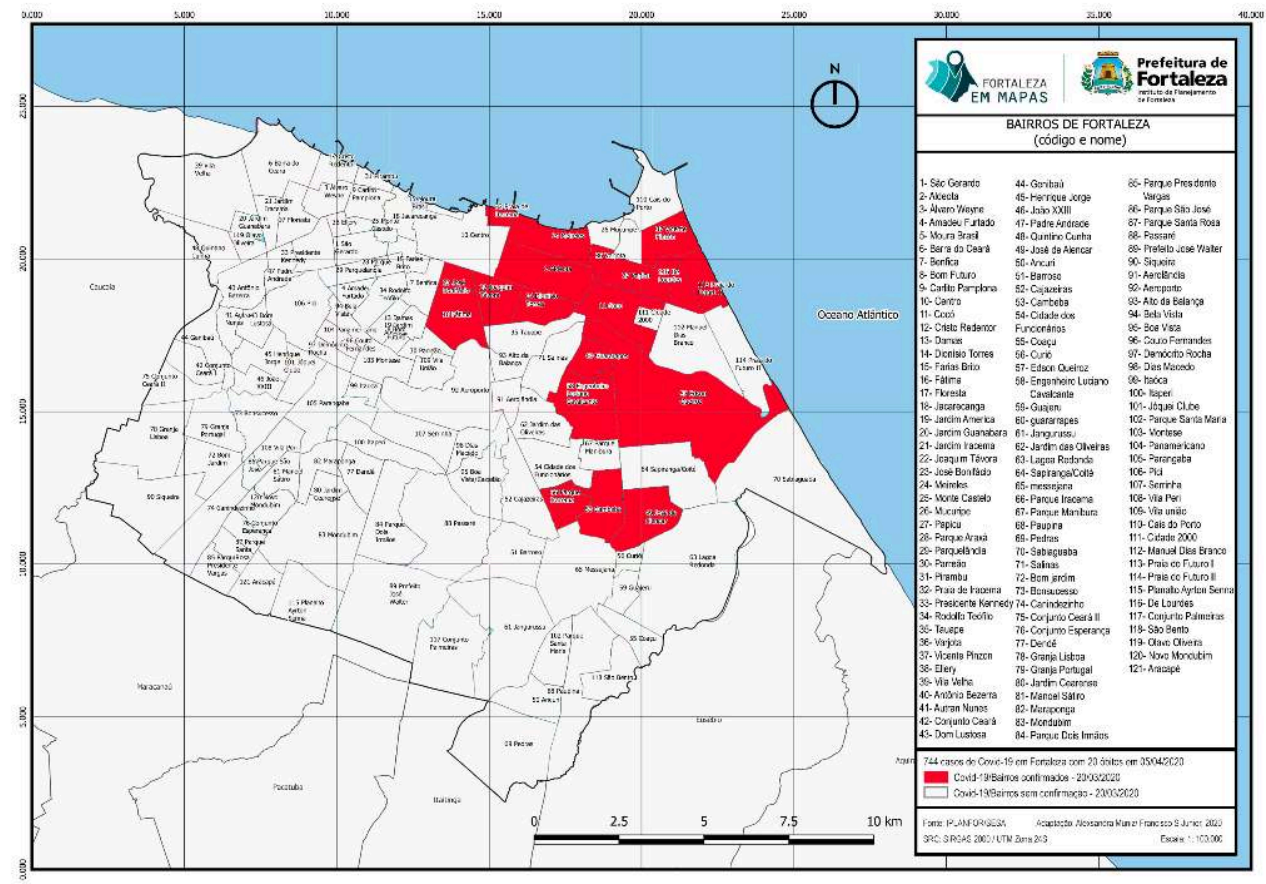

32 A Coordenadoria de Vigilância em Saúde (COVIS), da Secretaria Municipal de Saúde (SMS), no dia 20 de março quando se registrava 51 casos confirmados de Coronavírus 
em Fortaleza, informou que dos 121 bairros de Fortaleza, em 19(15,7\% dos bairros da cidade) foram registrados pelo menos um caso de Coronavírus.

Pela figura 7 é possível verificar os bairros onde foram registrados os casos em Fortaleza. A maior parte dos casos está na Regional II com um total de 13 bairros afetados pelo Covid-19, quais sejam: Meireles, Aldeota, Praia de Iracema, Joaquim Távora, Dionísio Torres, Varjota, Cocó, Papicu, Vicente Pinzón, Praia do Futuro I, De Lourdes, Guararapes, Engenheiro Luciano Cavalcante. A regional VI aparece logo em seguida com pelo menos um caso confirmado em 4 bairros: Edson Queiroz, Parque Iracema, Cambeba, José de Alencar. Os outros dois bairros são da Regional IV: Bairro de Fátima e José Bonifácio. Até este dia (20 de março) as regionais I, III, V Centro não tinham nenhum caso contabilizado.

No dia 02 de abril este quadro já muda, passando para 50 o número de bairros em Fortaleza onde foram registrados casos de Coronavírus, com destaque para o bairro Meireles conforme a Secretaria Municipal de Saúde (SMS) ${ }^{6}$.

35 A Regional II que se sobressai no número de bairros afetados é caracteristicamente marcada pela segregação social, aspecto emblemático da cidade de Fortaleza. Uma região com bairros que concentram boa estrutura física, belas avenidas e prédios, áreas verdes, serviços, comércio, bons equipamentos sociais e, ao mesmo tempo, localidades com estrutura urbana precária, sem a presença de equipamentos e ações de natureza pública.

36 A Secretaria Regional II é formada por 20 bairros, onde habitam 334.868 pessoas, correspondendo a $13,50 \%$ da população da capital. O perfil de pessoas infectadas é de adultos, inclusive pessoas assintomáticas, residentes em bairros de classe média e alta que viajaram para o exterior, como também para São Paulo ou Rio de Janeiro ou que tiveram contato com estas pessoas, ou seja, são casos importados de outros países ou estados por pessoas de classe social mais elevada e em bairros com maior IDH.

Vê-se pela figura 6 que os primeiros registros mostram a ocorrência em bairros de população com poder de compra médio e alto. Rapidamente o vírus se propagou por outros bairros da cidade. Esse quadro de carência tão presente cria situações delicadas nas extensas áreas periféricas, ocupadas de forma indevida por loteamentos clandestinos, não submetidos às normas urbanísticas exigidas pelos órgãos competentes da gestão municipal. As medidas tomadas contra a pandemia no Brasil copiam padrão adotado noutros países (China, Itália, Espanha, Rússia, Índia, Argentina, dentre outros) que consiste no fechamento de várias atividades como as dos setores do comércio e de serviços, atingindo duramente a economia urbana. São medidas severas voltadas à proteção das pessoas, de grande expressão social e péssimas para o desenvolvimento econômico. Especialistas em saúde pública, economistas e outros profissionais afirmam que não existe, até o momento, outra forma de se impedir a rapidez da propagação do vírus. Fortaleza tem um elevado número de desempregados ( $11,2 \%$ da população). Entre os ocupados, mais de $50 \%$ vive na informalidade com baixo rendimento financeiro. As políticas de transferência de renda atenuam o quadro de penúria de elevado contingente populacional da Região Metropolitana de Fortaleza. Com a pandemia do Coronavírus o quadro se agravou e as perspectivas não são favoráveis, dado que o governo central permanece duvidoso e inoperante em relação às medidas compensatórias. Os primeiros casos de contaminação ocorreram nos bairros de melhor IDH da cidade e todos os infectados tinham feito viagem ao exterior. Hoje a situação é diferente. $O$ vírus já está na periferia da cidade, quando se pensa na rapidez 
de seu contágio a preocupação aumenta, com áreas de grande densidade populacional somadas as piores condições sanitárias, a possibilidade do vírus se alastrar ainda mais é real, atingindo velozmente pessoas mais vulneráveis, sem esquecer o fato de que a estrutura hospitalar existente será incapaz de atender a demanda numa situação de pico da doença. Hospitais de campanha estão sendo construídos (em Fortaleza um total de 1.195 leitos em hospitais de campanha) e tanto na cidade, como no país está prevista uma considerável piora para os próximos meses de abril e maio. Com os setores econômicos mais dinâmicos da cidade operando com sérias restrições o aumento do desemprego ${ }^{7}$ e, consequentemente, da pobreza já é uma realidade. A cidade feérica que madruga com intenso movimento nas avenidas e ruas alterou, demasiadamente, sua aparência com escolas e universidades sem aulas presenciais. Restrições de funcionamento para o serviço de transporte e atividades que resultem em aglomerações e proximidade. Fortaleza ficou vazia, como se experimentasse um longo período de feriados, tendo, entretanto seus bares, restaurantes, teatros e cinemas fechados. Praias desertas, barracas fechadas nem de longe lembram o agito de poucas semanas atrás. Os hotéis acusam percentuais baixíssimos de ocupação, sendo que alguns fecharam por um período. $O$ setor de construção civil optou por férias coletivas. Os vôos reduzidos diminuíram o movimento do Aeroporto.

Somadas as ações na escala Federal, dentre as várias ações presentes no território cearense para enfrentamento ao Coronavírus no estado 8 tem-se:

通 A criação de um canal de comunicação pela Secretaria de Saúde do Ceará (Sesa) para facilitar o recebimento de doações no combate ao novo Coronavírus;

區 O investimento de $\mathrm{R} \$ 245$ milhões para reestruturação do sistema de saúde, aquisição de equipamentos e insumos;

噶 Aquisição de 350 mil testes rápidos para detecção do Coronavírus. Ademais, coletas estão sendo feitas no Centro de Eventos e sendo prioritárias para profissionais da saúde, com resultados para a doença entre cinco a dez minutos;

區 Isenção da conta de água para 338 mil famílias;

范 Suspensão da taxa de contingenciamento para 221 mil domicílios; antecipação do cartão mais infância para mais de 47 mil famílias;

[㖥 Cancelamento das férias de todos os profissionais de saúde do Estado;

萌 Treinamento e orientação das unidades hospitalares públicas e privadas do Ceará;

范 Solicitação ao Ministério da Saúde para habilitação de novos leitos de UTI para sete municípios: Itapipoca, Icó, Iguatu, Tauá, Crateús, Tianguá, Aracati;

落 A secretaria da Saúde criou o sistema Telesaúde $24 \mathrm{~h}$ onde a população pode tirar todas as dúvidas sobre prevenção ao Coronavírus e os sintomas da doença;

范 Criação do comitê estadual de enfrentamento a pandemia do Coronavírus no Ceará, que reúne 25 entidades/órgãos;

范 Articulação junto a Enel para suspensão dos cortes de energia durante o período de quarentena;

范 Lançamento do edital “Cultura Dendicasa”;

㽞 Vacinas estão sendo feitas também em forma de drive thru;

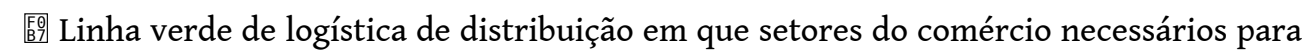
viabilizar o transporte de cargas podem funcionar; 


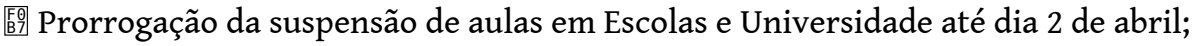

范 Para proteger a economia, o emprego, e principalmente, aqueles mais vulneráveis foi anunciado um pacote de medidas econômicas para auxílio as empresas, muitas já dando férias coletivas ou antecipando as férias, outras negociam com o trabalhador, outras demitindo como em Santa Quitéria a demissão de mais de mil funcionários da fábrica de calçados Democrata ${ }^{9}$ em meio a crise causada pela pandemia;

范 Suspensão de vôos internacionais para Fortaleza;

區 Barreiras de inspeção sanitária nas divisas do Ceará com Piauí, Paraíba, Rio Grande do Norte e Pernambuco;

范 Implementação de 574 leitos extras para atender pacientes em Fortaleza e no interior do Estado, como em: Sobral, Quixeramobim e Juazeiro do Norte.

8 Além do Hospital Leonardo da Vinci, no bairro aldeota que foi reativado exclusivamente para o tratamento da Covid-19, tem-se leitos extras para pacientes de Covid-19 nas estruturas anexas a hospitais de Fortaleza, tais como: Hospital Geral de Fortaleza, Hospital do Coração, Hospital Geral César Cals, Hospital Infantil Albert Sabin (HIAS), Instituto José Frota.

Quanto a rede de serviços de Saúde em Fortaleza, pela figura 8, dar para verificar a espacialização dos Hospitais e Upas em Fortaleza voltados ao Covid-19, notadamente nos bairros Aldeota, Papicu, Cristo Redentor, Barra do Ceará, Vila Velha, Antonio Bezerra, Parquelândia, Edson Queiroz, Parangaba, Itaperi, Conjunto Ceará, Messejana, Centro, Vila União. Ressalta-se que a localização no Estádio de futebol Presidente Vargas, no bairro Benfica deve-se a transformação deste em um hospital de 204 leitos, sendo 17 enfermarias, cada uma com 12 leitos para atender os casos de pacientes com Coronavírus, em Fortaleza. Ainda em construção, há previsão deste hospital de campanha iniciar o atendimento de pacientes a partir de 20 de abril.

Figura 8: Serviços de Saúde e o Covid-19

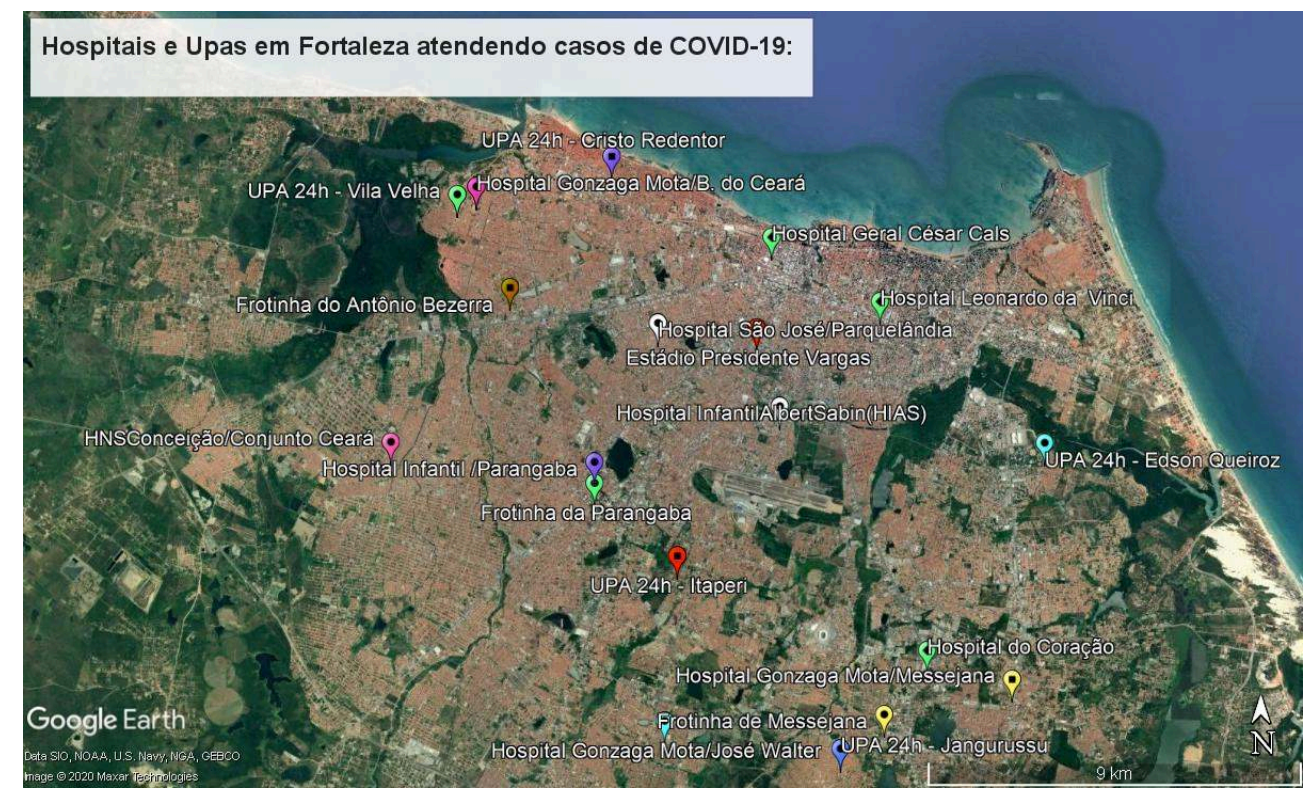

Fonte: GoogleEarth

Adaptação: Autores, 2020 
Paralelamente as medidas tomadas pelas autoridades locais, no contexto da sociedade em rede como bem afirma Castells(1999), redes de solidariedade são criadas esquecendo-se as diferenças, as crenças, em prol de um objetivo maior, mas como reflexo da sociedade de classes e das relações de poder, muitos entram em calorosos debates, muitas vezes não respeitando a diversidade de pensamento e a liberdade de expressão, desfocando do que realmente importa. A universidade lugar privilegiado da democracia também tem procurado se readaptar a presente realidade procurando na medida do possível considerar o percentual de alunos que não tem como corresponder a atividades remotas, buscando meios de não prejudicá-los, algumas atentando para especificidades locais, as situações de vulnerabilidade social e para o ensino de qualidade, seguindo as devidas regulamentações quanto ao ensino superior. Cientistas tem trabalhado intensamente em busca de uma vacina que venha frear a velocidade de propagação do Coronavírus, pesquisadores e docentes tem usado as redes sociais para difundir análises pertinentes quanto ao contexto atual em meio ao bombardeio de informações a cada segundo, que muitas vezes mais desinforma, incluindo aqui as fake news.

61 O momento proporciona introspecções e reflexões individuais na busca de saídas capazes de dar respostas à ansiedade e ao medo que afligem as pessoas. Divididos entre a ciência e a religião, muitos ressurgem fortalecidos na fé ${ }^{10}$ de que todo o pesadelo vivido logo estará no passado e que dias melhores virão, permitindo retornar a normalidade reinventados com o propósito de fazer a diferença nos diferentes territórios em que atua. Este fato só ratifica a afirmação de que a renovação da fé ${ }^{11}$ e o avanço da ciência caminham juntas, sendo necessário se fazer bom uso destas, explicitando a crítica construtiva com prudência, sabedoria e discernimento.

Principalmente nestes tempos difíceis é preciso manter o corpo e a mente sãos, respeitando os limites do próximo, sendo tolerantes ao tolerável, evitando fazer uso de expressões que só contribuem para aumentar o caos e o distanciamento social, vendo no meio técnico científico informacional e a explosão de diferentes posições e vozes a oportunidade de usar do desenvolvimento científico sem preconceitos ou hipocrisias, afinal cada um tem um papel na sociedade, saber exercê-lo é o que pede o presente contexto.

Já dizia Milton Santos em sua obra Por uma outra Globalização que é na contraracionalidade que se evidencia a voz, a vez, as ações e estratégias daqueles segmentos da sociedade que muitos teimam em deixar no invisível ou no esquecimento. É na escala local, no lugar mais próximo que o discurso se esmaece e que as contraracionalidades se evidenciam com mais força.

64 Diante do panorama que se apresenta, se por um lado procura-se preservar a vida, por outro com o fechamento do comércio e serviços não essenciais somado a desaceleração na circulação do capital na economia vigente, teme-se o agravamento ainda maior do que se apresenta, com a chegada de um quadro econômico recessivo.

65 O caos que se delineia é parte do processo de acumulação capitalista em seu movimento cíclico? Conforme Harvey "O capitalismo tende, ativamente, a produzir algumas das barreiras para o seu próprio desenvolvimento. Isso significa que as crises são endêmicas ao processo capitalista de acumulação" (HARVEY, 2005: 45) ${ }^{12}$.

66 Constata-se que o novo paradigma tecnológico/organizacional cuja característica essencial pode ser resumida em uma palavra, qual seja: flexibilidade(HARVEY, 1993) ${ }^{13}$, 
não consegue se consolidar como padrão sólido e universal, estando o desemprego, a inflação, a recessão, as pandemias, as catástrofes naturais e as dívidas públicas a revelarem a fragilidade da atual forma de acumulação capitalista.

Considerando que o capitalismo, como mostrou em toda sua história, que é no processo recessivo, que geralmente se segue às crises, que tem potencialidades de sobrevivência inerentes à sua lógica, tendo em vista que sua produção se move em contradições ou, como diria Marx, o capital é a contradição viva, somos levados ao seguinte questionamento: as características atuais seriam características de um momento de crise ou as ondas longas ${ }^{14}$ se tornaram cada vez mais curtas?

Não temos a pretensão, aqui, de trazer respostas e muito menos propostas de um presente que se encontra inacabado, mas procuramos entender o que se passa baseando-nos nos fatos e na literatura já existente.

69 A ciência contemporânea, face aos inúmeros problemas que afetam a sociedade, desenvolveu um campo específico denominado Gestão de Riscos. Na cidade, os riscos estão intimamente ligados às relações travadas entre sociedade e natureza. $\mathrm{O}$ descontrole urbano revela o conteúdo social do crescimento da cidade. A gestão de riscos na perspectiva de identificação de problemas e adoção de políticas públicas envolve vários sujeitos sociais, especialmente, técnicos, estudiosos, sociedade civil e governos. Como fazer a gestão de riscos face à uma pandemia?

\section{NOTAS}

1. Debora Diniz; Giselle Carino, A necropolítica das epidemias, El País, 09.03.2020. https:// brasil.elpais.com/opiniao/2020-03-09/a-necropolitica-das-epidemias.html. Acesso em 26.03.2020 2. https://g1.globo.com/mundo/noticia/2020/03/18/fechamento-de-fronteiras-por-coronavirusdificulta-volta-de-brasileiros-ao-pais.ghtml

3. ESCOBAR, Pepe, A China engalfinhada em uma guerra híbrida com os Estados Unidos, Btasil 247, 17.03.2020.https://www.brasil247.com/blog/a-china-engalfinhada-em-uma-guerra-hibridacom-os-estados-unidos. Acesso em 26.03.2020

4. https://www.saude.ce.gov.br/wp-content/uploads/sites/9/2020/02/

informe_diario_coronavirus_01_04_20.pdf

5. https://www.saude.ce.gov.br/wp-content/uploads/sites/9/2020/02/

informe_diario_coronavirus_01_04_20.pdf

6. https://www.opovo.com.br/coronavirus/2020/04/02/bairros-da-zona-nobre-concentramcasos-de-coronavirus-em-fortaleza.html

7. No Ceará, no dia 20 de março já chegava a 5.000 o número de trabalhadores de bares e restaurantes demitidos.

8. Maiores informações podem ser consultadas no Plano Estadual de Contingência Para Resposta às Emergências em Saúde Pública Novo Coronavírus(2019-nCoV)https://www.saude.ce.gov.br/ wp-content/uploads/sites/9/2020/02/plano_estadual_contigencia_corona_virus_2020.pdf

9. https://g1.globo.com/ce/ceara/noticia/2020/04/02/fabrica-de-calcados-democrata-demitemais-de-mil-funcionarios-em-unidade-do-ceara-meio-a-crise-da-covid-19.ghtml 
10. Ora, a fé é o firme fundamento das coisas que se esperam, e a prova das coisas que não se vêem. (Hebreus 11:1)

11. O problema dessa nítida separação entre "domínios do conhecimento que não se justapõem", como Stephen Jay Gould descreveu a ciência e a religião, é que a ciência possui o seu próprio sistema de crenças baseado na fé. http://g1.globo.com/Noticias/Ciencia/0,MUL195628-5603,00CIENCIA+E+UMA+QUESTAO+DE+FE+DEFENDE+PESQUISADOR.html

12. HARVEY, David. A Produção capitalista do espaço. Tradução de Carlos Szlak. São Paulo: Annablume, 2005(Coleção Geografia e Adjacências).

13. . Condição pós-moderna. São Paulo: Loyola, 1993.

14. Nos anos 20 do século XIX, Nicolai Kondratieff apresentou sua teoria sobre as curvas de longo prazo do desenvolvimento capitalista onde afirmou que os longos ciclos no sistema capitalista resultam de sólidos investimentos (fase A de expansão) ou de sua Depreciação (fase B de depressão).

\section{RESUMOS}

A pandemia provocada pelo novo Coronavírus colocou os territórios do mundo todo em alerta. Um complexo xadrez geopolítico insere esta pandemia no contexto de bruscas mudanças no cotidiano globalizado. Tendo como objetivo maior explicitar as consequências do Covid-19 no território brasileiro e em particular no Estado do Ceará, com ênfase em Fortaleza, sem perder de vista a intrínseca relação com o desenvolvimento do capitalismo e as desigualdades e contradições a este inerentes, realizou-se pesquisa bibliográfica e estatística com construção de mapas, gráficos e tabelas que permitiram a territorialização e evolução temporal comparativa. Dentre os resultados, tem-se que o Ceará é o terceiro Estado em número de casos. Isto deve-se não somente a intensificação destes, mas à rapidez da testagem, favorecendo a continuidade de implementação do plano Estadual estratégico. Na escala Estadual a concentração maior ocorre na capital, em bairros com maior IDH, onde residem pessoas de classe média e alta, sendo os demais casos na região metropolitana e interior do Estado com tendência para velocidade de difusão menos concentrada nos municípios do Estado. A Regional II que se sobressai na capital é marcada pela segregação social e espacial, aspecto emblemático da cidade de Fortaleza. Soma-se a isto, o fato do Coronavírus vir rapidamente se propagando para outros bairros da cidade, agravando ainda mais as precárias condições de moradia das periferias com desigual acesso às redes de abastecimento de água e esgotamento sanitário, atingindo notadamente os mais vulneráveis que são em maior número, o que é motivo de intensa preocupação, uma vez que o serviço de saúde não comportará tamanha demanda em curto espaço de tempo. 0 clima de pânico está instaurado e emerge a certeza que Fortaleza não será a mesma quando superada essa fase de expansão da contaminação. Conclui-se que o Coronavírus é mais que uma crise pandêmica, é também social, econômica, espacial, e, notadamente uma questão geopolítica, de luta de classes e aprofundamento do capitalismo em sua versão mais perversa.

The pandemic provoked by the new Coronavirus has put territories from all over the world under alert. A complex geopolitical game of chess inserts this pandemic in the context of sudden changes in the globalized daily life. Having as its higher goal making explicit the consequences of Covid-19 in the Brazilian territory and particularly the State of Ceará, emphasizing the city of Fortaleza, without losing from sight the intrinsic relation with the development of capitalism and 
its inherent inequalities and contradictions, bibliographical and statistic research was made with the elaboration of maps, graphs and charts that allowed for territorializing and comparative temporal evolution. Among the results, it was found that Ceará is the third state in Brazil in number of cases, and this is due not only to their intensification, but also to the swiftness of testing, favoring the continuity of implementation of the State strategic plan. In a state scale, the greatest concentration occurs in the capital, in districts with a higher HDI, where middle and high class individuals reside, the other cases being in the metropolitan region and inland with tendency for a less concentrated diffusion speed in the state municipalities. The Regional II which stands out in the capital is marked by social and spatial segregation, an emblematic aspect of the city of Fortaleza. In addition to it, the Coronavirus is quickly propagating to the city's other districts, further worsening the precarious living conditions in the peripheries, with unequal access to the networks of sanitation and water supply, notably affecting the most vulnerable, who are greater in number, which is a reason for intense concern, as the healthcare service will not be able to accommodate such a great demand in such a short period of time. The atmosphere of panic is installed and with it arises the certainty that Fortaleza will not be the same once this phase of contamination expansion is overcome. It may be concluded that the Coronavirus is more than an pandemic crisis, it is also a social, economic and spatial one, as well as notably a geopolitical question, of class struggle and intensification of capitalism in its most perverse version.

La pandémie provoquée par le nouveau Coronavirus a mis les territoires du monde entier sous alerte. Un complexe jeu d'échecs géopolitique insère cette épidémie dans le contexte de changements brusques dans le quotidien globalisé. En ayant comme objectif expliciter les conséquences du Covid-19 chez le territoire brésilien, en particulier dans l'état de Ceará, en soulignant la ville de Fortaleza, sans perdre de vue l'intrinsèque relation avec le développement $\mathrm{du}$ capitalisme et ses inégalités et contradictions inhérentes, on a réalisé une recherche bibliographique et statistique avec l'élaboration de cartes, graphiques et tableaux qui ont permis la territorialisation et l'évolution temporale comparative. Parmi les résultats, on a trouvé que Ceará est le troisième état du Brésil en nombre de cas. Cela est dû non seulement à leur intensification, mais aussi à la vitesse de la testage, favorisant la continuité de l'implémentation du plan stratégique de l'état. À l'échelle de l'état, la plus grande concentration est à la capitale, dans les quartiers avec un IDH plus élevé, où resident personnes de classe moyenne et haute, les autres cas dans la région métropolitaine et l'intérieur de l'état avec une tendance de vitesse de diffusion moins concentrée que chez les municipes de l'État. La Regional II que se démarque dans la capitale est caractérisée par la ségrégation sociale et spatiale, aspect emblématique de la ville de Fortaleza. Il faut ajouter à ça le fait que le Coronavirus se propage rapidement en direction à autres quartiers de la ville, en détériorant encore les précaires conditions d'habitation des périphéries avec un accès inégal aux réseaux d'approvisionnement et d'assainissement d'eau, en affectant notablement les plus vulnérables, qui sont plus nombreux ; c'est un motif d'intense souci, car le service de santé ne comportera une telle demande en si peu de temps. Le panique est installé et une certitude survient, celle de que Fortaleza ne sera plus la même quand cette phase d'expansion de contamination serait dépassée. On conclut que le Coronavirus est plus qu'une crise pandémique, en étant aussi sociale, spatiale, et, notablement, une question géopolitique de lutte de classes et de l'approfondissement du capitalisme en sa version plus perverse.

La pandemia causada por el nuevo Coronavirus ha puesto en alerta los territorios de todo el mundo. Un complejo ajedrez geopolítico inserta esta pandemia en el contexto de cambios repentinos en la vida cotidiana globalizada. Con el objetivo principal de explicar las consecuencias de Covid-19 en el territorio brasileño y en particular en el estado del Ceará, con énfasis en Fortaleza - sin perder de vista la relación intrínseca con el desarrollo del capitalismo y las desigualdades y contradicciones inherentes - tuvo lugar una investigación bibliográfica y 
estadística con la construcción de mapas, gráficos y tablas que permitieron la territorialización y la evolución temporal comparativa. Entre los resultados, se encontró que el Ceará es el tercer estado en número de casos. Esto se debe no solo a la intensificación del contagio, sino también a la rapidez en la realización de las pruebas y la identificación de los casos, lo que favorece la continuidad de la implementación del plan estratégico del Estado. En la escala regional, la concentración más alta ocurre en la capital, en barrios con un IDH más alto, donde residen las personas de clase media y alta, y los casos restantes en la región metropolitana e interiores del estado con una tendencia a una menor velocidad de difusión en los municipios. La Regional II que se destaca en la capital está marcada por la segregación social y espacial, un aspecto emblemático de la ciudad de Fortaleza. Sumado a esto, el hecho de que el Coronavirus se está extendiendo rápidamente a otros barrios de la ciudad, agravando aún más las precarias condiciones de vivienda de las periferias con acceso desigual a las redes de abastecimiento de agua y alcantarillado, llegando especialmente a los más vulnerables que son en mayor número, lo que es motivo de gran preocupación, ya que el servicio de salud no podrá satisfacer dicha demanda en un corto período de tiempo. El clima de pánico está establecido y surge la certeza de que Fortaleza no será la misma cuando se supere esta fase de expansión de la contaminación. Se concluye que el Coronavirus es más que una crisis pandémica, también es social, económico, espacial y, en particular, un tema geopolítico, de lucha de clases y profundización del capitalismo en su versión más perversa.

\section{ÍNDICE}

Mots-clés: Coronavirus, territoire, villes, capitalisme, Ceará.

Palabras claves: coronavirus, territorio, ciudades, capitalism, Ceará.

Keywords: Coronavirus, Territory, Cities, Capitalism, Ceará.

Palavras-chave: Coronavírus, Território, Cidades, Capitalismo, Ceará.

\section{AUTORES}

\section{JOSÉ BORZACCHIELLO DA SILVA}

Professor dos PPG em Geografia da UFC e da PUC-Rio

\section{ALEXSANDRA MARIA VIEIRA MUNIZ}

Professora Adjunta do Departamento de Geografia da Universidade Federal do Ceará 